HOMENAGEM DE VIDA

\title{
Lúcia Xavier: uma "pegada" radical contra as violações de direitos
}

\author{
Joilson Santana Marques Junior*
}

Antes de iniciar propriamente esse texto, peço licença. Faço isso, por entender que falar sobre uma mulher e, particularmente, uma mulher negra, sendo eu um homem negro gay, é uma honra e, ao mesmo tempo, um grande desafio. Mesmo que eu não pertença a uma forma hegemônica de masculinidade, ou melhor, que acredite não ser um representante oficial da forma de masculinidade que coopera para a exploração e opressão das mulheres em nossa sociedade, certamente reproduzo por força das ideologias dominantes (por mais que eu busque evitar) os machismos.

Sendo assim, esforcei-me nessas linhas para não tentar agir como porta voz, mas simplesmente, como alguém que vê e percebe uma trajetória admirável e profundamente marcante como a de Lucia Xavier: uma intelectual que foi forjada a partir de sua inserção racial, de classe e gênero, mas que, para além desses pertencimentos relacionados à sua própria história individual, abraçou causas muito além deles. É uma trajetória desenvolvida ao longo de quatro décadas de atuação pautada por princípios como a alteridade, a valorização da diversidade e a empatia na sua concepção mais radical, ou seja, como a compreensão de que o que oprime e explora o outro é da minha "conta", na medida em que "ninguém será livre enquanto alguém permanece cativo".

Assim, optei por uma abordagem que buscasse de maneira resumida contar um pouco da história, buscando uma perspectiva integral, que mescle a vida e o trabalho desenvolvido por Lúcia Xavier. É importante destacar que, em respeito à história de Lúcia tento reproduzir no texto, seu movimento de inserção simultânea em diversas frentes e temas, procurando uma abordagem que não segmentasse essas dimensões na vida dos/as explorados e oprimidos/as, como é próprio da vida dela.

Por fim, quero pontuar que os dados acerca de sua trajetória utilizados na construção deste texto foram produzidos também à entrevista/ conversa concedida por Lúcia a meu pedido em dezembro de 2015 e à consulta ao curriculum ${ }^{1}$ dela apresentado durante sua candidatura para a

\footnotetext{
* Assistente social (FSS/UERJ) e mestre em Ciências (IFF/FIOCRUZ).

1 Disponível em: <http://webcache.googleusercontent.com/search?q=cache:G4o42hDxnPol:www.portaldpge. rj.gov.br/Portal/sarova/imagem-dpge/public/arquivos/ouvidoria/eleicoes/lucia/Lucia_Curriculo.doc+\&cd=3\&hl=ptBR\&ct=clnk\&gl=br>. Acesso em: 13 dez. 2015.
} 
eleição da Ouvidora-Geral da Defensoria Pública do Estado do Rio de Janeiro, também ocorrida em $2015^{2}$.

\section{Encontros marcantes ou cruzando os caminhos com X de Xavier}

Conheci Lúcia em 2006, por intermédio da professora Magali da Silva Almeida ${ }^{3}$ minha orientadora de monografia de graduação e uma das principais pessoas de referência em minha formação profissional. Creio que já num primeiro momento fui atraído pelo jeito calmo, mas firme de Lúcia: uma fala contundente, mas profundamente terna, que transpira uma serenidade almejada por muitos, mas difícil de ser conquistada. Foi uma felicidade para mim, ainda aluno de graduação, saber que aquela pessoa tão elegante e séria era também assistente social.

Fui me encontrando com Lúcia no decorrer dos anos seguintes, particularmente nos eventos relacionados tanto à luta por direitos da população negra quanto nos da população LGBT e fui tendo com isso o prazer de ouvi-la e de conversarmos em alguns espaços de militância.

Até que na rearticulação da Comissão de Gênero Etnia e Diversidade Sexual (GEDS) do CRESS 7a $\mathrm{R}$, foi proposto um evento que simbolizava o retorno das atividades daquela Comissão. Lúcia foi então escolhida pelos membros da GEDS como conferencista principal, isto em razão da sua trajetória de atuação transversal nos temas da referida Comissão: o combate ao sexismo, ao racismo e à homofobia. Aquele evento foi ímpar, pois nele foi possível trazer para uma atividade especifica do CRESS (de cunho regional), a fala de uma assistente social extremamente atuante no combate a estas formas de opressão e exploração nas mais diversas frentes, inclusive internacionais. Naquele momento, Lúcia mostrou-se generosa e já uma grande parceira para futuras interlocuções.

Em 2012, a GEDS decidiu abordar o tema do racismo ambiental ${ }^{4}$ e, mais uma vez, decidimos pelo nome de Lúcia. Isso ocorreu porque ela

\footnotetext{
${ }^{2}$ Lúcia compôs uma lista tríplice de candidatos com Pedro Daniel Strozenberg e Nathalia Carlos da Silva. Os três nomes foram escolhidos a partir de votação por representantes da sociedade civil realizada no dia 09 de outubro de 2015.

${ }^{3}$ Atualmente, Magali da Silva Almeida é professora da UFBA e construiu sua trajetória profissional anterior na Faculdade de Serviço Social da Universidade do Estado do Rio de Janeiro (FSS/UERJ), tendo contribuído expressivamente ao longo de quase 30 anos, para as discussões étnico-raciais naquela instituição, entre outras.

${ }^{4} \mathrm{O}$ racismo ambiental como conceito é relativamente novo e tem sua origem nos Estados Unidos com a identificação, em fins da década de 1970 e início da de 1980, de situações que envolviam um dano coletivo e ambiental localizado em territórios majoritariamente negros e de outros grupos étnico/raciais discriminados, uma dessas situações foi a identificação nos Estados Unidos de que a maior parte dos aterramentos sanitários tóxicos estava localizava em comunidades negras empobrecidas. Para verificarmos isso também na realidade brasileira, basta pensarmos nas décadas de existência do Aterro Sanitário de Jardim Gramacho, em Duque de Caxias na Baixada Fluminense, território eminentemente negro e pobre, para onde durante anos foram destinados os dejetos da cidade do Rio de Janeiro (HERCULANO, 2008).
} 


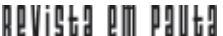

\} LÚCIA XAVIER: UMA "PEGADA" RADICAL - MARQUES JR., J. S. \}

DOI: $10.12957 /$ rep.2015.21076

havia também sido Consultora da $\mathrm{OXFAM}^{5}$ para a realização de um curso de formação de lideranças do movimento da reforma urbana, focado na discussão da inserção das dimensões de gênero e raça no orçamento público (entre 2010 e 2011). Ela foi convidada para o curso por ser protagonista do enfrentamento destas velhas questões travestidas em novas roupagens, como a reforma urbana (ao estilo Pereira Passos) em andamento na cidade do Rio de Janeiro, também naquele momento. Além disso, ela havia escrito há pouco tempo um artigo importante sobre as condições de vida das muIheres negras e a discussão do racismo ambiental.

Alguns anos à frente nos encontramos através do projeto Quero Fazer, um projeto da política de saúde de incentivo à testagem de HIV/ Aids. Eu havia trabalhado no mesmo projeto e conversamos um pouco sobre diagnóstico e tratamento de HIV/Aids no estado do Rio de Janeiro, principalmente sobre estudos que demonstram a relação entre sofrer homofobia e maior predisposição à infecção pelo HIV/Aids.

Por fim, para a elaboração desta homenagem, contei mais uma vez com a solicitude de Lúcia que conseguiu um espaço na sua concorrida agenda e no dia 18 de dezembro de 2015, fui recebido por ela na sede da Organização Não-Governamental Criola. Lá, me senti literalmente recebido em casa, pois foi com um sorriso e muito afeto que transcorreu toda a nossa conversa, embora não fosse uma entrevista na acepção mais rígida do termo. Foi uma conversa para conhecer e (re)conhecer essa mulher negra impressionante que se chama Lúcia Xavier.

Nesses diferentes encontros com Lúcia ao longo dos anos, tornouse patente para mim a luta empreendida por ela para melhorar as condições de vida daqueles/as que são historicamente discriminados/as e que, muitas vezes, são oprimidos/as mesmo entre os explorados: mulheres e homens negros, pessoas LGBT, pessoas soropositivas e vivendo com HIV/AIDS. Contudo, acima de tudo, o que chamou minha atenção ao longo do tempo foi que Lúcia não projeta a si mesma nem o que faz à dimensão de "paladina da justiça" ou no papel de "defensora dos outros". Ela reconhece a si mesma no/ a outro/a e é isso que a faz tomar partido nessas diferentes lutas. É o que a move.

\section{Lucia Xavier: nossos passos vem de longe ${ }^{6}$}

Lúcia Xavier nasceu Lúcia Maria Xavier de Castro em 1959. Sua infância foi marcada pela perda de seu pai, um radialista, quando ela tinha apenas dois anos e a luta de sua mãe para garantir a vida de Lúcia e de seus

\footnotetext{
${ }^{5}$ A Oxfam Internacional é uma confederação de 13 organizações e mais de 3000 parceiros que atua em mais de 100 países em projetos relacionados à pobreza e à injustiça social. Mais informações na página eletrônica: http:// www.oxfam.org.br/

${ }^{6}$ Tomo por empréstimo parte do titulo do livro organizado pela companheira de Lúcia Xavier na fundação da ONG Criola, Jurema Werneck, "O livro da saúde das mulheres negras: nossos passos vêm de longe".
} 


\section{ReVistg a}

\} LÚCIA XAVIER: UMA "PEGADA" RADICAL - MARQUES JR., J. S. \}

DOI: $10.12957 /$ rep.2015.21076

irmãos foi uma constante. Sua mãe tornou-se trabalhadora doméstica e, como tantas outras mulheres negras empregadas nesse setor, tinha uma jornada de trabalho extensa, sem direitos trabalhistas e contando com apenas duas folgas no mês para ficar com seus filhos, o que a motivou a matriculálos/as em um colégio interno no bairro Lins de Vasconcelos, zona norte do Rio de Janeiro, onde Lúcia passou uma boa parte de sua infância.

Embora tendo iniciado a infância em condições adversas, Lúcia fez questão de enfatizar a existência do cuidado em sua família, principalmente o auxílio de sua avó à mãe de Lúcia e a outras mulheres em situações semelhantes. É interessante notar que a solidariedade das mulheres (e aqui faço uma referência particular às mulheres negras trabalhadoras), expressão de resistência presente ao longo da formação sócio histórica brasileira, foi uma marca presente também na vida de Lúcia desde o inicio de sua vida, já que esses laços " de muitas maneiras " eram as formas de proteção social existentes diante da ausência do Estado e da proteção social pública.

Foi também graças a esse tipo de solidariedade entre mulheres que, através de uma mulher que frequentava o mesmo espaço religioso de matriz africana frequentada que a mãe de Lúcia conseguiu uma inserção no mercado de trabalho, não mais como doméstica, mas no comércio varejista, e assim ela pôde se mudar para a Tijuca, para uma casa de cômodos e ter um pouco mais de tempo de descanso, inclusive para conviver com seus/suas filhos/as.

Lúcia começou, como tantas outras adolescentes negras, a trabaIhar adolescente, com 14 anos, na década de 1970, tornando-se uma aluna trabalhadora ainda no científico (atual ensino médio). Ela teve seus primeiros contatos com discussões politicas (e, por conseguinte, de acesso a direitos) quando com outros/as alunos/as formou um grupo de estudo e debates de textos de orientação marxista. O grupo se encerrou com a intervenção da diretora do colégio que o proibiu, visto o contexto de ditadura.

Lúcia inicialmente pretendia cursar Direito, mas uma amiga trouxe a ela um folder que apresentava o curso de Serviço Social, convencendoa de que ela gostaria daquele curso. Quando viu a grade curricular do curso, ela de fato se empolgou, pois "eram matérias as mais variadas: filosofia, estatística, história." e acredita que ao olhar a grade curricular se identificou com a multiplicidade de conhecimentos associados ao mesmo curso.

Na Faculdade de Serviço Social da Universidade Federal do Rio de Janeiro - UFRJ (e, também, na Universidade Federal Fluminense - UFF/ Campos, pois cursou alguns períodos também naquela instituição), Lúcia foi costurando suas várias frentes de militância e a ação político-profissional.

Lúcia foi uma "aluna trabalhadora" nos mais diversos trabalhos durante sua graduação. Trabalhou no comércio de artigos religiosos de matriz africana entre outros segmentos do comércio e realizou ainda várias outras formas de trabalho remunerado, contanto que essas garantissem seu tempo para estar nas aulas, nos estágios e outras atividades acadêmicas. 


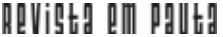

\} LÚCIA XAVIER: UMA "PEGADA" RADICAL - MARQUES JR., J. S. \}

DOI: $10.12957 /$ rep.2015.21076

Ao mesmo tempo, a jovem transitava pelos bailes Black Soul, que contribuíram na organização politica dos/as jovens negros/as no fim dos anos de 1970 e início de 1980. Através daquele movimento, Lúcia passou a fazer parte de um grupo organizado de militantes na Cidade de Deus (favela da zona oeste da cidade do Rio de Janeiro) chamado "Acorda Criola" que durou um curto período.

Ao mesmo tempo, ela se envolveu nas atividades do Centro Acadêmico de Serviço Social (CASS/UFRJ e CASS/UFF-Campos) e apoiou a construção do Partido dos Trabalhadores (PT). A seguir, ela passou a fazer parte do IPCN (Instituto de Pesquisa de Cultura Negra) ${ }^{7}$, onde também se envolveu com o trabalho em dois núcleos: o Núcleo Negro e o Núcleo de Luta Comunitária.

Premida pela necessidade de sobrevivência " ainda como estudante universitária "Lúcia foi aprovada com sucesso num concurso público específico para trabalhar em uma instituição de atendimento aos então chamados de "menores". Foi naquele momento, que ela se envolveu intensamente com o campo de defesa dos direitos das crianças e adolescentes, numa conjuntura brasileira em que movimento por estes direitos logrou maior êxito, com a aprovação em 1990 do Estatuto da Criança e do Adolescente (ECA).

O curso de Serviço Social também contribuiu para o traçado singular do caminho de Lúcia, como por exemplo, a disciplina de Estágio Supervisionado e a de Movimentos Sociais, que também contribuiu para a sua intensa relação com o campo da militância e da luta por direitos.

Uma de suas primeiras experiências de estágio foi realizada na Associação de Moradores da Rocinha, à época altamente combativa. Era o período de surgimento da discussão de assessoria aos movimentos sociais na profissão, favorecendo a proximidade do campo profissional com a teoria social crítica e a busca de uma intervenção marcada pelo envolvimento com as lutas sociais.

A experiência de estágio naquele campo foi tratada por Lúcia como também definidora de sua trajetória posterior. Já que ela lembra situações como da atuação da assistente social (sua supervisora) que contribuiu de forma efetiva para que um adolescente conseguisse realizar o sonho de "criar" seus irmãos, pois este tinha perdido os pais e estava na eminencia de perder sua própria casa. Ao relembrar esta situação em particular, Lúcia destaca a importância da entrevista, da orientação e da estratégia traçada junto com o adolescente pela profissional: a realização de um acompanhamento que extrapolava a relação burocrática com o usuário. Esta condução técnico-operativa balizada por uma perspectiva ético-política emancipatória, assim como a densidade da relação teoria/prática também apreendida

${ }^{7}$ O IPCN foi declarado como Instituição de Utilidade Pública Municipal em junho de 1984 e destacou-se em muitos momentos no combate ao racismo. 


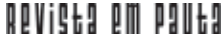

\} LÚCIA XAVIER: UMA "PEGADA" RADICAL - MARQUES JR., J. S. \}

DOI: $10.12957 /$ rep.2015.21076

nos campos de estágio, foi destacada por Lúcia como elementos apreendidos do Serviço Social que a acompanharam em todos os outros cargos e funções que ocupou até hoje.

Lúcia ressaltou ainda que tendo participado intensamente da luta por direitos de crianças e adolescentes e do Movimento Nacional de Meninos e Meninas de Rua, ela se envolveu, posteriormente a sua formatura em 1984, nos debates e da construção do Estatuto da Criança e do Adolescente (ECA), da Constituição Federal de 1988 e da Constituição do Estado do Rio de Janeiro. Foi também seu envolvimento com as questões relacionadas às meninas negras que a levou a participar em 1992, junto Thereza Antônio de Castro, Guaraciara Matilde Werneck, Josina Maria da Cunha e Jurema Pinto Werneck, outras mulheres negras, que fundou Criola, uma das instituições mais respeitadas nacionalmente e internacionalmente no combate ao racismo e ao sexismo, dentre outras violações dos direitos humanos e que tem a bandeira da igualdade e da equidade como ponto chave de sua atuação.

Ao longo dos seus 24 anos de existência, Criola destacou-se na luta contra o racismo, o sexismo e a homofobia, através de ações de intervenção direta nos espaços públicos democráticos, de mobilização comunitária, de estudos e pesquisas e no campo internacional e nacional dos direitos humanos e do feminismo negro. Assim, podemos perceber Criola como uma típica "organização não-governamental militante", nos termos de Maria da Glória Gohn:

as próprias ONGs são também muito diferentes entre si, quanto aos seus objetivos, projetos, formas de atuação e ação coletiva, paradigmas e estilo de participação que adotam; e, fundamentalmente, pressupostos político ideológicos que alicerçam suas práticas (tanto as discursivas e como as ações concretas) (...) procuramos demarcar as diferenças entre dois tipos de ONGs nos anos 90: as ONGs oriundas ou herdeiras da cultura participativa, identitária e autônoma dos anos 70/80, a qual denominaremos de militantes (2013, p.244).

Em sua página eletrônica, Criola segue atualmente definindo sua atuação a partir da defesa e da promoção de direitos das mulheres negras "em uma perspectiva integrada e transversal" que visa à inserção das mesmas como agentes de transformação, contribuindo para a construção de uma sociedade em que sua contribuição seja acolhida como um bem da humanidade.

Recentemente, Criola notabilizou-se pelo desenvolvimento da campanha pública "Racismo virtual: as consequências são reais". Através dela, frases racistas postadas nas redes sociais "diante da falsa sensação de anonimato" ganharam vida nas ruas de Porto Alegre, do Rio de Janeiro $(\mathrm{RJ})$, de Americana (SP), de Vila Velha (ES), de Feira de Santana (BA) e de Guarulhos (SP). Elas foram estampadas em outdoors próximos à residência 


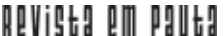

\} LÚCIA XAVIER: UMA "PEGADA" RADICAL - MARQUES JR., J. S. \}

DOI: 10.12957/rep.2015.21076

de seus autores, mas preservando a identidade dos mesmos, na perspectiva de demonstrar que o seu anonimato é relativo e favorecendo seu processo de reflexão.

\section{Interseções: todos os caminhos convergem na encruzilhada}

De 1991 a 1997, Lúcia Xavier dedicou-se também à função de assessora parlamentar com enfoque na área de movimentos sociais, tendo sido uma das assistentes sociais pioneiras na experiência de assessoria parlamentar, com um direcionamento para os movimentos sociais e no campo dos direitos humanos, com ênfase no combate aos processos de exclusão baseados nas relações de gênero, raça/etnia, classe social e geração, orientação sexual, condição de saúde, entre outras.

Desse modo, Lúcia também constituiu um fazer profissional comprometido com o projeto ético-político do Serviço Social contemporâneo que, entre outros aspectos, elege o combate à discriminação e às desigualdades sociais. Nesse ponto da entrevista, Lúcia enfatizou ainda a importância dos conteúdos da formação profissional para o exercício da assessoria parlamentar, embora deixasse claro que foi sua atuação anterior junto aos movimentos sociais que a conduziu àquela função e não o contrário.

Isso é importante dado o fato de que a assessoria no Poder Legislativo possibilita a proposição de projetos e ideias que podem viabilizar melhores condições de vida para a população geral e, no caso de sua trajetória, para o combate à violação dos mais variados direitos, como por exemplo, na sua intensa participação no processo de organização do Disque Defesa Homossexual (DDH), serviço inaugurado de forma inovadora no país em 1999, esse projeto foi pioneiro no Rio de Janeiro ao propor atendimento público a pessoas LGBT que eram discriminadas e que serviu de base para a constituição de outros serviços semelhantes no país.

A partir da constituição de Criola, Lúcia passou a atuar em duas frentes unidas, porém com espacialidades diferentes: a assessoria parlamentar onde pôde expressar as demandas identificadas ao longo do seu trabalho, vivências e observação da vida concreta dos sujeitos, e a ação direta a partir de Criola que a mantinha em contato direto com sujeitos subalternizados e, principalmente, com as sujeitas subalternizadas: mulheres negras, pauperizadas, por vezes lésbicas, outras vezes portadoras de HIV/Aids, crianças, jovens ou adultas, de modo que sua atuação se retroalimentou em um movimento cíclico de quem atua junto à população e quem pode se colocar como um canal de mobilização junto à Assembleia Legislativa do Estado do Rio de Janeiro (ALERJ).

Por sua vez, em consonância com os com os objetivos de Criola e da assessoria parlamentar e como síntese de sua atuação, ela se tornou uma das organizadoras do processo de preparação da III Conferência Mun- 


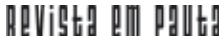

\} LÚCIA XAVIER: UMA "PEGADA" RADICAL - MARQUES JR., J. S. \}

DOI: $10.12957 /$ rep.2015.21076

dial de Combate ao Racismo, à Xenofobia e Intolerâncias Correlatas, ocorrida em Durban (África do Sul) e realizada pela ONU em 2001. A seguir, ela se tornou também revisora da importante Declaração de Durban e de seu Plano de Ação ${ }^{8}$.

As pegadas que Lúcia vem deixando em seu caminho se traduzem também em muitos de seus escritos que passara a sistematizar as lutas sociais nas quais se envolveu. Assim, sua produção textual que se iniciou em 1991, dialogando com o direito à vida (não apenas como acesso à renda, mas também como acesso às políticas sociais), principalmente tendo por foco homens e mulheres negros/as trabalhadores/as, crianças e adolescentes negros/as e pauperizados/as (e o alcance reduzido de sua cidadania formal), bem como a discussão das temáticas relativas ao HIV/Aids.

Seu trabalho como assessora parlamentar se encerrou quando ela tomou posse no cargo de Subsecretária Adjunta de Defesa da Cidadania em 2002. Como gestora pública, Lúcia Xavier pôde ainda conduzir algumas propostas no âmbito da política de segurança pública, ainda que como ela mesma ressalte, tenha enfrentado inúmeros entraves na própria máquina pública, como o racismo e o sexismo institucional, o desfinanciamento acentuado das políticas sociais numa orientação neoliberal, entre outros. Contudo, Lúcia no tempo de sua gestão, que durou cerca de oito meses, procurou contribuir com uma visão da política de segurança pública, onde o Estado atua em uma perspectiva protetiva dos sujeitos, principalmente daqueles/as que sofreram mais historicamente com os processos de discriminação e violência e não para oprimi-los.

Em 2003, Lúcia Xavier trabalhou também na Relatoria da seção "O direito à saúde" do projeto DESCH (Plataforma Brasileira de Direitos Econômicos Sociais e Culturais) da Organização das Nações Unidas (ONU), contribuindo para reafirmar a saúde como direito fundamental dos sujeitos, colocando na ordem do dia o acesso à saúde e a qualidade dos serviços de saúde, defendendo esta como politica pública de primazia do Estado.

Da experiência de atuação no DESCH, Lúcia Xavier também guardou histórias reais de pessoas cujo direito à saúde foi definitivamente violado, como o de: "uma mulher que não conseguia falar diretamente sobre a LER (Lesão do Esforço Repetitivo), mas apenas conseguia dizer do sonho que alimentava antes, em ser desenhista (inclusive que a levou para esta empresa), mas que em virtude do tipo de trabalho lá desenvolvido, adquiriu a referida doença e não pôde mais desenhar" e, também, "a de um homem que relatou a dor de não poder mais carregar seu filho nos braços, pois também havia desenvolvido uma doença ocupacional que o impossibilitava de carregar peso em qualquer proporção".

Este trabalho em particular demandou de Lúcia a utilização de maneira intensa da capacidade de escuta e de relatar com densidade - tão

${ }^{8}$ Para uma maior discussão dos efeitos desta Declaração, cf. Saboia \& Porto (2015). 


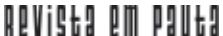

\} LÚCIA XAVIER: UMA "PEGADA" RADICAL - MARQUES JR., J. S. \}

DOI: 10.12957/rep.2015.21076

necessárias a assistentes sociais" visto que seu trabalho estava centrado na produção dos relatórios que descreviam as graves violações ocorridas no campo da saúde em suas variadas dimensões, tais como a saúde do trabalhador, a saúde da mulher, a saúde da população negra, nas instituições públicas, dentre outras.

Nesse compasso, a produção bibliográfica de Lúcia Xavier foi tornou-se focada cada vez mais na saúde, no direito a ela, tendo a transformação social e o combate ao racismo como eixo destes seus escritos, onde as diferentes discussões vão se entrelaçando e abarcando novos temas, na mesma medida em que todas representam discussões importantes do campo da cidadania e da luta por direitos das mulheres negras e dos demais grupos subalternizados.

Ao longo de sua história, a atuação politica de Lúcia Xavier fezse notar tanto pela ação direta, como pela sua representação em Conselhos de Políticas Públicas e em outros espaços de participação social, como o Conselho da Igualdade racial, da Criança e do adolescente, o Global Found For Women. Nestes espaços, ela manteve a preocupação com o estímulo à participação política como parte integrante do desenvolvimento das ações e da estratégia de pressão politica pela construção de direitos no solo concreto da vida.

A formação como assistente social, como dito, também se constituiu como um pano de fundo que acompanhou toda a trajetória de Lúcia. Desde antes da fundação de Criola, seu trabalho já possuía, por exemplo, forte cunho socioeducativo. Com a criação de Criola, essa dimensão se fortaleceu através dos projetos de educação para a cidadania voltados para as mulheres negras em seus mais variados ciclos de vida.

No decorrer desta trajetória, as atividades socioeducativas se desdobraram em muitos processos de qualificação de gestores/as e trabaIhadores/as dos mais variados órgãos públicos e privados, em especial para as questões relacionadas ao racismo em suas diversas expressões e atravessamentos, à discriminação de gênero, a LGBTfobia e ao HIV/Aids.

E por fim, a preocupação com a avaliação dos trabalhos desenvolvidos apareceu como um eixo privilegiado não só pelas ações desenvolvidas por ela através de Criola, nas atividades de relatoria e assessoria/ consultoria de que participou, mas também pela sua participação na avaliação e seleção de projetos de intervenção nas áreas já mencionadas, o que possibilitou também orientar/contribuir para a formação de muitos/as daqueles/as que estão iniciando suas trajetórias na área ou que já desenvolvem trabalhos nela.

Atualmente, Lúcia permanece uma das coordenadoras da ONG Criola e atua como técnica da Gerência Estadual de DST/Aids, Sangue e Hemoderivados da Saúde da Secretaria de Estado de Saúde (SES-RJ) e, mais uma vez, vem demonstrando o compasso ético-político de sua inserção profissional, encampando as lutas por maior acesso a diagnóstico e trata- 


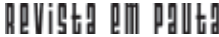

\} LÚCIA XAVIER: UMA "PEGADA" RADICAL - MARQUES JR., J. S. \}

DOI: 10.12957/rep.2015.21076

mento em HIV/Aids, a promoção da saúde da população negra e LGBT, mesmo diante de uma política de saúde cada vez mais subfinanciada e, em grande medida sucateada. Ao mesmo tempo, Lúcia permanece também conselheira do Global Found for Womem e membro da Comissão de Seleção de Projetos do Fundo Elas dedicado ao apoio a projetos sociais que tomem como questão central o fortalecimento das mulheres.

As palavras de Lúcia Xavier permanecem ressoando, enquanto penso na importância de trajetórias de assistentes sociais como ela que, entre outras tantas habilidades, acumulou a habilidade para o diálogo interdisciplinar. Quando refletimos sobre as expressões da questão social, não podemos deixar de considerar sujeitos reais, que sofrem, choram se emocionam, passam privações diversas, em suma, essas expressões precisam ser enfrentadas, precisamente porque elas estão postas na vida cotidiana dos sujeitos e produzem sofrimento.

Com sua trajetória, Lúcia nos convida a olhar para os sofrimentos oriundos da exploração econômica, da discriminação pelo racismo, das assimetrias entre homens e mulheres, da discriminação motivada pela orientação sexual e pela identidade de gênero, da intolerância religiosa, da violação dos direitos das crianças e adolescentes, do desfinanciamento das políticas sociais, da discriminação por ter HIV/Aids... com sua trajetória, Lúcia nos convida a enfrentá-las. Enfrentá-las, pressupõe habilidade e criticidade para a reinvenção permanente da profissão, logo gostaria de finalizar esta homenagem com o registro de uma frase da própria Lúcia acerca das bases teóricas de sua formação como assistente social e que potencializaram toda sua trajetória: "A teoria critica é um estímulo ético de enfrentamento ao conservadorismo profissional".

\section{Referências}

BRASIL. Programa Nacional de Prevenção as DST/AIDS do Ministério da Saúde. Rede Aidsinformação. BOLETIM TOQUES, volume 2, n. 1-12, 1996.

CASTRO, Lúcia Maria Xavier. Direito à Vida. Revista Tempo e Presença, n. 258. São Paulo, julho/agosto, 1991, pág. 24 - 25.

- Das Medidas Específicas de Proteção. In: O Estatuto da Criança e do Adolescente Comentado - Comentários Jurídicos e Sociais. São Paulo. Malheiros Editores Ltda. 1992. 


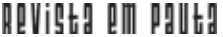

\} LÚCIA XAVIER: UMA "PEGADA" RADICAL - MARQUES JR., J. S. \}

DOI: 10.12957/rep.2015.21076

CASTRO, Lúcia Maria Xavier. Exclusion and Death in Brazil. WISE News Comunique Vol. 387/8, WISE, Amsterdam, março 1993, p.16-17.

. Mulher Negra: Sua Situação na Sociedade. In: Guia de Direitos do Brasileiro Afrodescendente. Rio de Janeiro: CEAP, 1999 (Cadernos CEAP).

. Claudia uma Flor de Mulher. In: WERNECK, Jurema, WHITE, Evelyn C. e MENDONÇA, Maísa (org.). O Livro da Saúde das Mulheres Negras Nossos Passos Vêm de Longe. Rio de Janeiro, CRIOLA/ Pallas Editora, 2000.

. Mulheres Negras: os Direitos Humanos como um Paradigma Ético da Humanidade. In: Anais do Seminário Nacional de Psicologia e Direitos Humanos (2000, Brasília, DF) Psicologia e direitos humanos. Práticas Psicológicas: Compromissos e Comprometimentos. São Paulo: Casa do Psicólogo, 2001.

. I Conferência Nacional de Políticas para as Mulheres: Primeiro passo para reverter às desigualdades de gênero e raça. Revista $A$ Abong na I Conferência Nacional de Políticas para as Mulheres, Brasília junho de 2004.

Superar o racismo também é um problema de saúde pública. In: BRASIL. Ministério da Saúde. Saúde e Direitos Humanos. Fundação Osvaldo Cruz, Núcleo de Direitos Humanos e Saúde - Brasília: Ministério da Saúde, 2004.

. Anais do Seminário Soberania e Cidadania. "Mesa Diversidade Cultural, Cidadania e Direitos Humanos". In: Fala: Cadernos de Cidadania - $n$. 1(2006). Rio de Janeiro: UERJ, Faculdade de Direito, CCBLS, 2006.

. Movimento Negro: Contra o Racismo e pela Transformação "Social": In Movimentos Sociais com a Palavra. Revista Democracia Viva, nº 32. IBASE, RJ: de julho a setembro, 2006.

- Implicações do Racismo no Tráfico de Pessoas. In: SANTOS, Eloísa Gabriel dos, SILVA, Maria do Socorro Nunes da, DELLADONE, Priscila Siqueira (orgs.). Tráfico de Pessoas: uma Abordagem Política. São Paulo: Serviço à Mulher Marginalizada - SMM, 2007 [Coleção Caderno SMM].

. O Papel do Conselho Nacional de Promoção da Igualdade Racial na Gestão da Política de Igualdade Racial. In: WERNECK, J. (org.). Mulheres Negras: um olhar sobre as lutas sociais e as políticas públicas no Brasil. CRIOLA, RJ: 2008.

. O movimento de mulheres negras e a construção de movas concepções para a transformação social. In: ANDRADE, P.; SILVA, C. (orgs.). Cadernos de Crítica Feminista. Recife: SOS Corpo - Instituto Feminista para a Democracia, ano IV n. 3. Dez 2009, página 28-42.

. Desafios e perspectivas para os jovens negros brasileiros. In: MOTA, A.; ROCHA, R. (orgs.). Educação e Juventudes: construindo cidadania. Cader- 


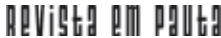

\} LÚCIA XAVIER: UMA "PEGADA" RADICAL - MARQUES JR., J. S. \}

DOI: 10.12957/rep.2015.21076

nos de Educação Popular, n.30. Rio de Janeiro: Nova - Pesquisa e Assessoria em Educação, 2010, p.63-77.

. Mulheres Negras por Justiça Socioambiental. In: Brasil. Presidência da República. Secretaria de Políticas para as Mulheres. Edição Especial da

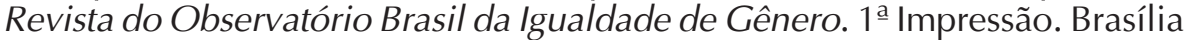
Secretaria de Políticas para as Mulheres, 2012. 87p.

; CAMILO, M.; BONFIM, N. O que dá menos trabalho. Revista do CEAP, nำ 2. Rio de Janeiro. Coedição CUT, outubro 1991, pág. 31 e 32.

CASTRO, L. M. X. de; FREITAS, S. (org.). Mulheres de Brasília e do Rio de Janeiro no Monitoramento da Política Nacional de Enfrentamento à Violência contra as Mulheres. Rio de Janeiro: CFEMEA e CRIOLA, 2010.

CASTRO, L. M. X. de; ROCHA, L. O. Nossos Passos vem de Longe. Revista Proposta, no 189, ano 29. FASE, RJ: junho a agosto, 2006.

GOHN, M. G. Sociedade civil no Brasil: movimentos sociais e ONGs. Revista Meta: Avaliação. Rio de Janeiro: vol. 5, n.14, mai-ago 2013, p. 238253.

HERCULANO, S. O clamor por justiça ambiental e contra o racismo ambiental. INTERFACES - Revista de Gestão Integrada em Saúde do Trabalho e Meio Ambiente - São Paulo, v.3, n.1, Artigo dois, jan./ abril 2008.

KAMEL, L.; SALVATERRA, B.; XAVIER, L. Vulnerabilidades, AIDS e DST entre Mulheres no Estado do Rio de Janeiro. In: GOVERNO DO ESTADO DO RIO DE JANEIRO. Secretaria de Estado de Saúde. SVEA/Gerência de DST/AIDS, Sangue e Hemoderivados. AIDS e Violência Sexual: políticas de enfrentamento. Fev., 2013 (coleção de texto no 8).

MORAES, A. F.; ROCHA, C.; RAMIREZ, F. M.; CASTRO, L. M. X. de. A Menina, a Vida e a Cidade. Revista de Cultura Vozes, volume. 85(LXXXV). Petrópolis: Editora Vozes, setembro/outubro, 1991, pág. 517 -535.

ONG CRIOLA. CAMPANHA RACISMO VIRTUAL: CONSEQUÊNCIAS REAIS. Disponível no endereço eletrônico: http://www.racismovirtual.com.br/ra cismo-virtual. Acesso em dez. 2015.

RIBEIRO, I.; CASTRO, L. M. X. Entre a Descentralização Necessária e a Representação Reivindicada: Algumas Considerações sobre a Cidadania da Criança e Adolescentes Pobres. Grupo de Trabalho Família e Sociedade, Sessão: Família e Cidadania. Anais do XVIII Encontro Anual da ANPOCS. Caxambu, 23 a 27 de novembro de 1994.

SABOIA, G. V.; PORTO, A. J. V. A Conferência Mundial de Durban e o Brasil. Disponível em: http://dc.itamaraty.gov.br/imagens-e-textos/DHPortugues03.pdf. Acesso em novembro de 2015. 


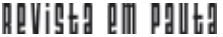

\} LÚCIA XAVIER: UMA "PEGADA" RADICAL - MARQUES JR., J. S. \}

DOI: 10.12957/rep.2015.21076

XAVIER, L. Racismo, religião e meio ambiente. In: CORRÊA, A. M.; COSTA, L. M.; BARROS, J. F. P. (orgs.). A floresta: educação, cultura e justiça ambiental. Rio de Janeiro: Garamond, 2013.

XAVIER, L.; WERNECK, J. Mulheres e Trabalho: o que mudou para as muIheres negras no mercado de trabalho? In: VENTURI, G.; RECAMÁN, M.; OLIVEIRA, S. (orgs.). A Mulher Brasileira nos Espaços Público e Privado. São Paulo: Fundação Perseu Abramo/ Edições SESC SP, 2013, p 257-278.

DOI: $10.12957 /$ rep.2015.21076

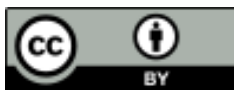

A Revista Em Pauta: Teoria Social e Realidade Contemporânea está licenciada com uma Licença Creative Commons Atribuição 4.0 Internacional. 